\title{
NARRATIVE ESSAYS
}

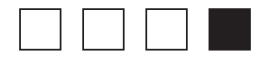

\section{The Lonely Only: Physician Reflections on Race, Bias, and Residency Program Leadership}

Camille B. Garrison, MD

(Fam Med. 2019;51(1):59-60.)

doi: 10.22454/FamMed.2019.339526

$\mathbf{M}$ y earliest memory of wanting to become a doctor was when I was 8 years old. Dr R. saw me watching him intently as he examined my little brother's ear. He peeked up at me over the otoscope and asked if I wanted to look. From that day forward, he inquired at subsequent visits if I still wanted to be doctor, which led to more detailed discussions about what I would need to do to achieve my goal. Dr R. probably didn't know how important those discussions were for me, but I sensed that he believed that I too could become a physician one day. Throughout my childhood, I worried that it would be difficult for a person who looked like me to become a physician, as I didn't personally know any physicians with my racial identity.

As a child, my image of a physician was an Indian man, like Dr R. I identify myself as an African-American female physician and I am often in situations where I am the only person bearing that identity in the room. I consider myself the "Lonely Only" because I am the only AfricanAmerican faculty in my residency program, the only one among our family medicine residency program leadership, the only one on our hospital leadership team, and the only one in most instances when it comes to my role as physician. I've had numerous experiences with implicit and explicit bias and personal racism in the workplace and have experienced the emotional burden that comes with being the Lonely Only. My responses to these experiences have evolved as I have progressed in my career, through gaining a better understanding of the environments in which I've worked, and in finding my voice to affect that environment when racial issues emerged. Now 9 years postresidency, I am the program director for an urban underserved family medicine residency program in one of the most segregated metropolitan cities in the United States. My experiences as a Lonely Only have led me to accept responsibility for addressing issues of racism and the associated health disparities we see in medicine in my role as program director, specifically through resident education, faculty development, patient care, and community engagement. I strive to address these issues daily.

A few years ago, I had an encounter with one of my colleagues that served as the catalyst for me in confronting issues of bias and racism within my own program. I was having small talk with another faculty in our precepting room and mentioned something I recently saw on the news. There was a shooting at a private suburban school and I mentioned how shocking this was to me. My colleague wasn't shocked at all. As I sat there wondering why he wasn't surprised, he answered my question. "Well, more and more black kids go to that school now." My immediate response was "Well, they never said anything about the race of the shooter." He looked at me with a blank stare as if there was nothing wrong with his comment. I was mortified, embarrassed, and furious all at the same time. I was concerned for the resident sitting next to me and wondered if any medical students or staff could've been passing by hearing our discourse. I was also saddened by thinking about the patients that he took care of and if he really held the belief that more black people equates to more violence.

The rest of the evening I reflected on several experiences I had in the past as a physician where I was reminded of my race. I remembered my former faculty taking a piece of

From the Medical College of Wisconsin Department of Family and Community Medicine, and Columbia St Mary's Family Medicine Residency. 
cellophane tape and sticking it on my skin to see if any pigment came off on the tape. I thought about the times that I'd been referred to as "homegirl" in professional settings by other faculty members. I thought about the time when one of my advisees told me that she felt intimidated by my feedback because she didn't have much previous experience with black women and "how we are," demonstrating what she meant by smacking her lips and giving me a quick neck roll. These memories brought forth so many unresolved emotions and feelings of sadness, anger, and shame (for being silent), that I knew this time I had to do something.

The following week, I called the program director to inform him of my concern and asked that he be present for the meeting with my colleague. Our meeting started with an explanation of how the comments made me feel as an African-American woman and mother of AfricanAmerican boys. I talked about our predominately African-American patients and staff and how they might have perceived his comments. He repeatedly stated that he didn't mean to offend me and that he didn't see me in "that way." I explained to him the way I see myself and the way I believe the world sees me, as an African-American woman first. I talked about how differently people might think of him when he walks outside of our clinic doors, as they might assume he's a doctor, while I might not be considered a physician at all, simply because of my race. It was at that moment that he started to understand, and he apologized.

Did my colleague intend to offend me by his comment? I don't think so. But that's how implicit bias works. If we are not in tune with our personal biases and how to stop biased thinking as it occurs, those thoughts will eventually be expressed in the open. I felt empowered after speaking to my colleague that day and it helped prepare me for future encounters, as I began to see incidents where I was reminded of my skin color as opportunities to intervene, rather than as burdens.

Early in my career, I experienced the friction that can come from leading these discussions and acknowledge that at times it comes with personal costs. In the past, I felt isolated when colleagues tried to discourage me from having discussions at our program about racism and felt misunderstood when sharing my personal experiences with racism. I even felt overlooked when leadership opportunities became available and wondered if that had to do with my race. I started thinking, "Why do I always have to be the one initiating conversations about racism and biases?" until I shifted my focus to what was most important for our patients. Our patients need providers who understand the racial factors affecting their health and who can address them in an equitable way, limiting bias. As program director, I've found ways to teach our physician team that learning about the impact of racism is imperative to addressing the health disparities that our patients face. I teach that these disparities can be addressed through individual patient encounters, mentoring underrepresented minority residents, implementing curricular changes in our community medicine education, enhancing community engagement activities, and leading related resident didactics and faculty development sessions.

It took some time before any formal teaching occurred in my program after my implicit bias incident. I was a more junior faculty member when the event took place. However, 1 year later, I became the program director and started making small changes within our program, teaching more on our underserved patient population and health disparities. I later hosted discussions regarding the physician role and the Black Lives Matter movement, facilitated a clinic-wide viewing of the Milwaukee 53206 documentary (set in my childhood neighborhood) highlighting inequities in incarceration rates and poverty and allowed for a new resident-led social justice group. In 2017, I partnered with another physician working in a similar residency program setting (who is also an underrepresented minority) and we developed a workshop on racism that we facilitated at both of our programs this past year.

It has been heartening to see the influence of efforts in these areas, as our residents and faculty have taken steps to learn, discuss, teach, and practice medicine with better understanding of racism and bias. In some ways, I have come to accept being the Lonely Only, now willing to share my experiences as an African-American physician, because for our program, racism has become a topic that is open for discussion and intervention. I have learned how to navigate being a Lonely Only through seeking opportunities to build skills to recognize unresolved emotions and by using coaching, mentoring, and other resources when confronting racism, both indirectly and directly. I have chosen to fully embrace the responsibilities of being the Lonely Only, as the downstream impacts of my efforts can have enormous implications for the care of my patients and the health of my clinic community.

CORRESPONDENCE: Address correspondence to Dr Camille Garrison, Columbia St Mary's Family Medicine Residency Program, 1121 E North Ave, Milwaukee, WI 53212. 414-267-6502. Fax: 414-267-3892. cgarrison@mcw.edu. 